\title{
Monitoring Antifungal Agents of Artemisia annua against Fusarium oxysporum and Fusarium solani, Associated with Panax notoginseng Root-Rot Disease
}

\author{
Yu-Nan Ma ${ }^{1}$, Chuan-Jiao Chen ${ }^{1}$, Qing-Qing Li ${ }^{1}$, Fu-Rong Xu ${ }^{1}$, Yong-Xian Cheng ${ }^{2, *}$ \\ and Xian Dong ${ }^{1, *}$ \\ 1 College of Pharmaceutical Sciences, Yunnan University of Traditional Chinese Medicine, \\ Kunming 650500, China; mayunan994727@163.com (Y.-N.M.); chenchuanjiao663@163.com (C.-J.C.); \\ leecmm@163.com (Q.-Q.L.); xfrong99@163.com (F.-R.X.) \\ 2 School of Pharmaceutical Sciences, Shenzhen University Health Science Center, Shenzhen 518060, China \\ * Correspondence: yxcheng@szu.edu.cn (Y.-X.C.); dongxian_1655129@163.com (X.D.); \\ Tel.: +86-135-1056-1051 (Y.-X.C.); +86-158-8782-6242 (X.D.)
}

Received: 14 December 2018; Accepted: 3 January 2019; Published: 8 January 2019

check for updates

\begin{abstract}
Root rot of Panax notoginseng has received great attention due to its threat on the plantation and sustainable utilization of $P$. notoginseng. To suppress the root-rot disease, natural ingredients are of great importance because of their environment friendly properties. In this study, we found that the methanol extract from Artemisia annua leaves has strong antifungal effects on the growth of Fusarium oxysporum and Fusarium solani resulting into root-rot disease. Essential oil (EO) thereof was found to be the most active. GC-MS analysis revealed 58 ingredients and camphor, camphene, $\beta$-caryophyllene, and germacrene $\mathrm{D}$ were identified as the major ingredients. Further antifungal assays showed that the main compounds exhibit various degrees of inhibition against all the fungi tested. In addition, synergistic effects between $A$. annua $\mathrm{EO}$ and chemical fungicides were examined. Finally, in vivo experiments were conducted and disclosed that $P$. notoginseng root rot could be largely inhibited by the petroleum ether extract from $A$. annua, indicating that $A$. annua could be a good source for controlling P. notoginseng root-rot.
\end{abstract}

Keywords: Artemisia annua; essential oil; Panax notoginseng; root rot; Fusarium oxysporum; Fusarium solani

\section{Introduction}

Panax notoginseng is a perennial herb (Araliaceae). Its dry roots and rhizomes are used as medicinal parts known as San-Qi in Chinese. The main component of P. notoginseng is saponin. Relevant research showed that notoginseng saponin and heat-transformed ginsenoside have inhibitory activity against Epidermophyton floccosum, Trichophyton rubrum, and Trichophyton mentagrophytes [1]. Due to its great demands in cardiovascular diseases, it has been cultivated in Wenshan City of Yunnan Province for more than 400 years, where the planting area and yields have reached over $90 \%$ those of our country [2]. However, serious problems of continuous cropping obstacles (CROs) occur during cropping, resulting in decreased yields and loss of quality of $P$. notoginseng [3]. CROs could be resulted from multiple factors, of which, the root-rot disease caused by a single pathogen or a combination of pathogens could not be ignored. It is the most destructive and could result in yield reduction, no harvest, and a loss of active ingredients [4]. The pathogen fungi in the P. notoginseng rhizosphere have been investigated, indicating that $F$. solani, F. oxysporum, and $C$. destructans are the main pathogens of $P$. notoginseng root-rot disease [5-7]. Therefore, efforts targeting these fungal species might be helpful for discovering new agents against $P$. notoginseng root-rot disease. At the present, botanical fungicides 
have demonstrated their advantages owing to their eco-friendly property. In this regard, essential oils (EOs) of aromatic plants have recently received increased attention due to their low toxicity towards mammalians and high biodegradability [8]. China is rich in natural plant resources, which is one of the important ways to obtain new fungicides.

Artemisia annua L., a plant belonging to Asteraceae family, is a traditional Chinese herb mainly used for the treatment of malaria. Compounds such as artemisinin, artemisinic acid, and coumarins are characterized from this herb [9]. The medicinal ingredients in A. annua are non-volatile and volatile [10]. The non-volatile components are mainly artemisinin, artemisinic acid, coumarin, and other compounds, which are sesquiterpenoids compound. Some research revealed that Sesquiterpene lactones exhibit a wide range of biological activities, such as antitumor, anti-inflammatory, analgesic, antiulcer, antibacterial, antifungal, antiviral, antiparasitic, and insect deterrent [11]. Previous studies showed that $A$. annua EO has a broad antibacterial spectrum [12,13]. Moreover, the whole plant of A. annua has been used to prevent $P$. notoginseng root-rot by local people in Wenshan of Yunnan Province, China. The aim of the paper was to conduct an investigation to unveil the agents responsible for root-rot disease of $P$. notoginseng. In this paper, we describe our efforts on antifungal tests of A. annua.

\section{Materials and Methods}

\subsection{Plants Cultivation}

P. notoginseng seeds were seeded in sterile quartz sand and roseite with a 1:2 mixture in greenhouse. After germination, seedlings were cultivated under $20{ }^{\circ} \mathrm{C}$ with a relative humidity of $70 \% \pm 10 \%$ and a photoperiod of $14 \mathrm{~h} \mathrm{day}^{-1}$. The seedlings were supplied with full-strength Hoagland nutrient solution. The macronutrient composition of the Hoagland nutrient solution (in $\mathrm{mg} \cdot \mathrm{L}^{-1}$ ) was $40 \mathrm{~N}$ (as $\mathrm{NH}_{4} \mathrm{NO}_{3}$ ), $10 \mathrm{P}$ (as $\mathrm{KH}_{2} \mathrm{PO}_{4}$ ), $40 \mathrm{~K}$ (as $\mathrm{K}_{2} \mathrm{SO}_{4}$ and $\mathrm{KH}_{2} \mathrm{PO}_{4}$ ), $57 \mathrm{Ca}\left(\right.$ as $\mathrm{CaCl}_{2}$ ), and $40 \mathrm{Mg}$ (as $\mathrm{MgSO}_{4}$ ). The basal micronutrient composition (in $\mathrm{mg} \cdot \mathrm{L}^{-1}$ ) was $2.0 \mathrm{Fe}$ (as Fe-EDTA), $0.2 \mathrm{~B}$ (as $\left.\mathrm{H}_{3} \mathrm{BO}_{3}\right), 0.5 \mathrm{Mn}\left(\right.$ as $\left.\mathrm{MnCl}_{2} \cdot 4 \mathrm{H}_{2} \mathrm{O}\right), 0.05 \mathrm{Mo}$ [as $\left(\mathrm{NH}_{4}\right)_{6} \mathrm{Mo}_{7} \mathrm{O}_{24} \cdot 4 \mathrm{H}_{2} \mathrm{O}$ ], $0.01 \mathrm{Zn}\left(\right.$ as $\left.\mathrm{ZnSO}_{4} \cdot 7 \mathrm{H}_{2} \mathrm{O}\right)$, and $0.01 \mathrm{Cu}\left(\right.$ as $\left.\mathrm{CuSO}_{4} \cdot 5 \mathrm{H}_{2} \mathrm{O}\right)$. Dicyandiamide, a nitrification inhibitor, was added to each nutrient solution to prevent oxidation of ammonium.

A. annua seeds were provided by the Yunnan Institute of Agricultural Science and Drug Research (Kunming, Yunnan, China). Seedlings were cultivated under $25{ }^{\circ} \mathrm{C}$ with full exposure. After the seedlings growth to $70 \mathrm{~cm}$, the plants were harvested for use.

\subsection{Preparation of Fungal Culture}

The pathogenic fungi were isolated from the diseased $P$. notoginseng and identified as Fusarium oxysporum and Fusarium solani, by Sangon Biotech (Shanghai) Co., Ltd. (Shanghai, China). Then the two pathogens were cultured on potato dextrose agar (PDA) medium at $28{ }^{\circ} \mathrm{C}$ in the dark for seven days.

\subsection{Pathogenicity Determination and Microscopic Observation of the Pathogenic Fungi}

The conidia suspension of the fungi were prepared according to the method described by Hao [14]. The healthy $P$. notoginseng seedlings were submerged in a conidial suspension containing $1 \times 10^{6} \mathrm{cfu} / \mathrm{mL}$ for $2 \mathrm{~h}$. Then the negative control plants were treated with the sterile water. After infection, the P. notoginseng plants were continually cultivated in the greenhouse. After approximately 20 days of growth, the numbers of $P$. notoginseng diseased plants were counted. The mycelium and conidia of the two pathogens were put into a temporary slide for microscopic observation. Then the morphology of hyphae and conidia were observed under optical microscope (Olympus Corporation, Tokyo, Japan). 


\subsection{Preparation of Methanol Crude Extract from A. annua}

The roots, stems and leaves of $A$. аnnua were completely separated and dried under natural conditions, then the samples were crushed into powders with a pulverized machine. The different parts powders $(50 \mathrm{~g})$ were put into a triangle bottle, and $450 \mathrm{~mL}$ different concentrations of methanol $(0 \%, 25 \%, 50 \%, 75 \%, 100 \%)$ were added. A $600 \mathrm{~W}, 40 \mathrm{kHz}$ sonicator (Model: 15D793, Ningbo Scientz Biotechnol Co., Ltd., Ningbo, Zhejiang, China) was used for ultrasound-assisted extraction. The samples were ultrasonic for $2 \mathrm{~h}$ and static for half an hour at $37^{\circ} \mathrm{C}$. During the extraction process, the sample container was held in a thermostat-controlled water bath. Then the extraction processes were repeated three times. After extraction, the crude extract was filtered and stored at $4{ }^{\circ} \mathrm{C}$ for use.

\subsection{Determination of Antifungal Activity of A. annua Crude Extract In Vitro}

The oxford cup method was adopted to determine the effects of $A$. annua crude extract on the growth of pathogens mycelia [15]. Two pathogens were cultured on PDA medium for five days, then a $5 \mathrm{~mm}$-wide disc of fungi containing agar was excised from the culture margins, which was placed in the middle of the petri dishes. The four oxford cups were placed in the same distance around the fungi discs, which the distance between the oxford cup and the middle of petri dish was $25 \mathrm{~mm}$. Then the crude extract was filtered through $0.22 \mu \mathrm{m}$ hydrophobic membranes, and the sterile filtrate extract was obtained. The filtrate extract of $200 \mu \mathrm{L}$ was added to every oxford cup. Different concentrations of methanol were used as the negative control. Each treatment was repeated three times. Then the pathogens were cultured in the incubator at $28{ }^{\circ} \mathrm{C}$ for seven days, and the diameter of colony was measured based on the average value of two perpendicular diameters. The inhibitory effect of the crude extract on pathogenic fungi was shown by histogram.

\subsection{Preparation of EO and Non-Volatile Fractions from A. annua Leaves}

The sample of $100 \mathrm{~g} \mathrm{~A}$. annua leaves powder was placed in a flask with a round bottom, and $1200 \mathrm{~mL}$ distilled water was added. Then the sample was soaked for half an hour. EO was extracted by steam distillation and distilled at $100{ }^{\circ} \mathrm{C}$ for $6 \mathrm{~h}$. The steam distillation apparatus consisted mainly three parts, which were steam equipment, condensation equipment and oil collection equipment. After the extraction, the EO was collected, dehydrated with anhydrous sodium sulfate and stored in a brown sample bottle, named as II (EO). After extraction, the residues were filtered and the water part was concentrated, which was named as III (water soluble part). The filtered residues were extracted with methanol by ultrasonic twice, and the mixtures were concentrated and dried, named as IV. An aliquot of sample IV was suspended in water and extracted with equal volume of chloroform thrice, and the chloroform layer was concentrated and dried to obtain V. The water layer was concentrated to be VI. Sample was obtained by direct ultrasonic extraction using methanol, which was VII. All the samples were stored at $-20{ }^{\circ} \mathrm{C}$ for further analysis.

\subsection{Antifungal Effect of Fractions II-VII from A. annua Leaves}

Fractions II-VII obtained from A. annua leaves were dissolved in a mixture solution of 10/1000 DMSO and 1/1000 Tween 80, and the final concentration of components was $50 \mathrm{mg} / \mathrm{mL}$. Meanwhile, $10 / 1000$ of DMSO and 1/1000 of Tween 80 mixed solution (I) was used as the negative control. The effects of $A$. annua leaves different extract on pathogenic fungi were carried out according to the oxford cup method above.

\subsection{Analysis of A. annua EO by GC-MS}

The EO were analysis by GC-MS with an HP-5 MS quartz capillary column $(30 \mathrm{~mm} \times 0.25 \mathrm{~mm}$ $\times 0.25 \mathrm{~mm}$ ) (Agilent Technologies, Santa Clara, CA, USA) [16]. Helium (1.2 mL/min) was used as carrier gas. The injector temperature was set at $250^{\circ} \mathrm{C}$. An initial column oven temperature of $80^{\circ} \mathrm{C}$ was 
elevated to $240{ }^{\circ} \mathrm{C}$ at a rate of $3{ }^{\circ} \mathrm{C} / \mathrm{min}$ and held for $50 \mathrm{~min}$. The mass spectrometer (MS) conditions were as follows: transfer line temperature at $250{ }^{\circ} \mathrm{C}$, ion source at $230{ }^{\circ} \mathrm{C}$, acquisition mass range $30-500$, and the ionization potential at $70 \mathrm{eV}$. Then the relative peak area percentages of the different compounds were calculated based on the FID data. The identification of the analyzed compounds were accomplished by comparing their mass spectra with those of authentic compounds available from computerized spectral database (NIST).

\subsection{Determination of Minimum Inhibitory Concentration (MIC)}

The MIC values test was carried out by 96-well plates [17]. The A. annua EO, main components and two kinds of chemical fungicides (Flutriafol and Hymexazol) were diluted with 20/1000 of DMSO and 1/1000 of Tween 80 solutions by double dilution method. A. annua EO had 12 groups of solution with a final concentration range $(37.50-0.04 \mathrm{mg} / \mathrm{mL})$, then the chemical fungicides and main compounds (L-camphor; DL-camphor, $\beta$-caryophyllene and camphene) with a final concentration range $(2.5-0.005 \mathrm{mg} / \mathrm{mL})$ were also prepared. Conidia suspension was prepared with a 1/4 PDB culture. The number of microconidia was measured by blood cell counting board, with final concentration of $1 \times 10^{4} \mathrm{cfu} / \mathrm{mL}$. A mixture formed from filter-sterilized EO $(50 \mu \mathrm{L})$ and suspension of the fungi $(150 \mu \mathrm{L})$ were added to the wells of 96-cell plate. Then $150 \mu \mathrm{L}$ suspension and $50 \mu \mathrm{L}$ solution that included 20/1000 DMSO and 1/1000 of Tween 80 was added to the wells as a negative control. The 96-well plates were kept at a constant temperature of $28^{\circ} \mathrm{C}$ for $36 \mathrm{~h}$. After the incubation period, the wells were checked for fungi growth. The absorbance of each well was measured at $595 \mathrm{~nm}$ by using a microplate reader (Model: 1510, Thermo Fisher Scientific, Waltham, MA, USA).

\subsection{Synergistic Effects Observation of A. annua EO and Chemical Fungicides}

The checkerboard microdilution assay was used to evaluate the mixed solution effect [18]. MIC values were measured according to the above step. Then a two dimensional checkerboard with serial two fold dilutions of each compound was used, and the concentration ranged from 1/16 $\times$ MIC to $8 \times$ MIC. Different concentrations of EO and different concentrations of hymexazol or flutriafol (each $25 \mu \mathrm{L}$ ) were combined into the each well. Each well contained a mixture of two drugs with different concentrations, and suspension of the fungi $(150 \mu \mathrm{L})$ was added to the well. The $150 \mu \mathrm{L}$ suspension of the fungi and $50 \mu \mathrm{L}$ solution that included 20/1000 DMSO and 1/1000 of Tween 80 as a negative control. Then the 96 -well plates were kept at a constant temperature of $28{ }^{\circ} \mathrm{C}$ for $36 \mathrm{~h}$. After the incubation period, the wells were checked for fungi growth. The absorbance of each well was measured at $595 \mathrm{~nm}$ by using microplate reader (Model: 1510, Thermo Fisher Scientific, Waltham, MA, USA). MIC determination of combined drugs use: the concentration of drugs corresponding to wells growing without fungi was used as the MIC of EO combined with hymexazol or flutriafol.

FIC of $A$. annua $\mathrm{EO}=\mathrm{MIC}$ of $A$. annua $\mathrm{EO}$ in combination with chemical fungicides $/ \mathrm{MIC}$ of A. annua EO alone, FIC of chemical fungicides = MIC of antifungal in combination with EO/MIC of chemical fungicides. FICI = FIC of $A$. annua $\mathrm{EO}+$ FIC of chemical fungicides. The types of effects were classified as follow: FICI $\leq 0.5$, synergism effect; $0.5<$ FICI $\leq 1$, additive effect; $1<$ FICI $\leq 4$, irrelevant effect and FICI $>4$, antagonism [19].

\subsection{Preparation of Petroleum Ether Extract from A. annua Leaves}

The A. annua leaves powder was extracted by $85 \%$ ethanol with reflux, then ethanol was distilled to obtain concentrated solution. The equal volume of water and petroleum ether were added to the concentrated solution soaking for $12 \mathrm{~h}$, then the petroleum ether layer was extracted. The operation was repeated for three times. Then the crude petroleum ether extract from A. annua was prepared by decompression recovery of petroleum ether. 


\subsection{The In Vivo Effect of Petroleum Ether Extract from A. annua on the Incidence of P. notoginseng}

The sterilized quartz sand and roseite were mixed in proportion of 2:1 as P. notoginseng culture medium. The petroleum ether extract was mixed into the matrix, and the concentrations were $0.25 \mathrm{mg} / \mathrm{g}$ and $0.5 \mathrm{mg} / \mathrm{g}$. The healthy $P$. notoginseng seedlings were submerged in a mixed conidial suspension containing $1 \times 10^{6} \mathrm{cfu} / \mathrm{mL}$ of both $F$. oxysporum and $F$. solani for $2 \mathrm{~h}$. Six P. notoginseng plants were planted into a pot. The culture medium without petroleum ether extract was set as a negative control. Three replicates was performed. After 20 days of infection by the pathogenic fungi, the plants were graded for severity of wilt disease as 0 (not showing chlorosis), 1 (the stem soft), 2 (the stem fallen, but the leaf not wilted), and 3 (plant wilting). The wilting rate $(\%)=$ the number of wilting plants/total number of plants $\times 100$. Disease index $=\sum$ (rating $\times$ number of plants rated) $/$ (total number of plants $\times$ highest rating) $\times 100[20]$.

\subsection{Statistical Analysis}

Statistical analysis was performed with SPSS Statistics 19.00 (SAS Institute, Cary, NC, USA) by using one way ANOVA and Duncan's multiple comparisons test.

\section{Results}

\subsection{Pathogenic Determination and Microscopic Observation of Pathogenic Fungi}

Two pathogenic fungi were cultured on PDA medium for seven days. F. oxysporum grew into a round colony (Figure 1, 1a) with an average diameter of $70 \mathrm{~mm}$, and the colonies changed from white to pink. The hyphae were villous. Under microscope, small conidia and hyphae could be clearly seen. The small conidia was oval or round (Figure 1, 1b), and the size was $(7.3-18 \mu \mathrm{m}) \times$ $(3.3-5.7 \mu \mathrm{m})$. The mycelium was abundant and the surface was smooth, and small conidia were produced (Figure 1, 1c). The colony of $F$. solani was round, and the mycelium was white or pale yellow. The mycelium of $F$. solan $i$ was flocculent and grew vigorously (Figure 1, 2a). Small conidia was sickle shaped or long column shaped (Figure 1, 2b), with a size of $(10-18 \mu \mathrm{m}) \times(3-5 \mu \mathrm{m})$. The mycelium was straight, long, and smooth (Figure 1, 2c). After P. notoginseng pathogen infection, the above ground part of the plants was short and the leaves turned yellow. The surface of stem was dry, and the root rot was obvious (Figure 1, 1d and 2d).

A

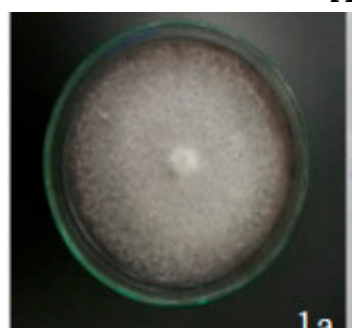

$1 \mathrm{a}$

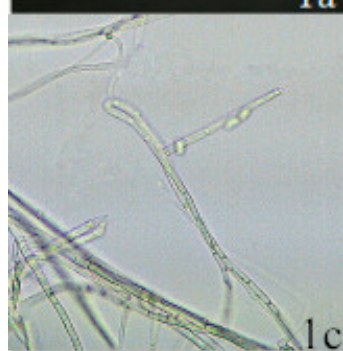

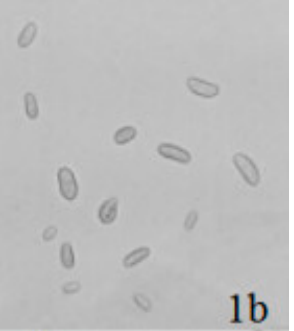

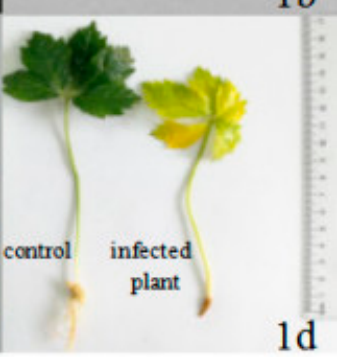

B

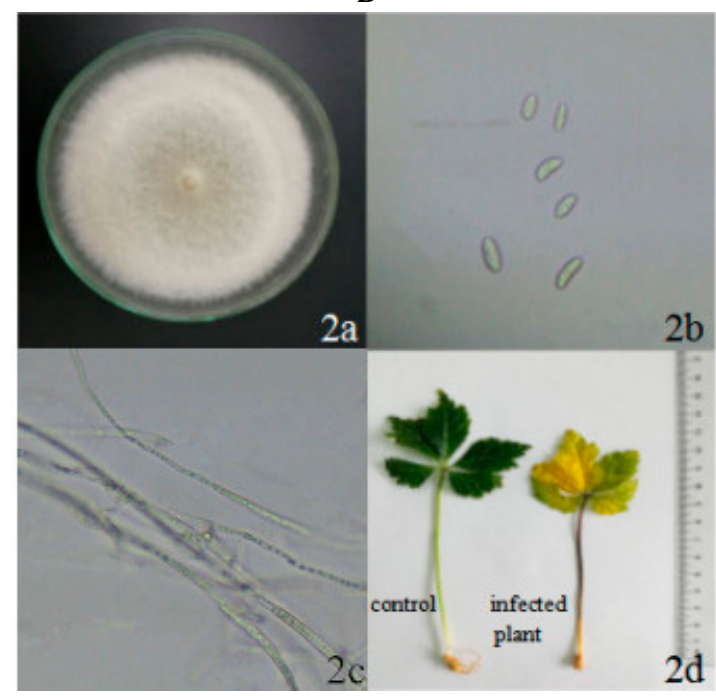

Figure 1. Microscopic observation of F. oxysporum, F. solani and infection of P. notoginseng. (A): F. oxysporum. (B): F. solain. (a) colonial morphology; (b) microconidia; (c) mycelium form; (d) P. notoginseng plants infected by pathogenic fungi. 


\subsection{Inhibitory Effect of Methanol Crude Extract from A. annua on Pathogenic Fungi}

Inspired by the wisdom of local people and to tracking antifungal agents of $A$. annua, first, the methanol extracts of different plant parts were prepared and examined for their inhibition on the growth of the fungi. As shown in Figure $2 \mathrm{~A}_{1}, \mathrm{~A}_{2}$ ). The extracts of the roots and the stems from A. annua have no inhibitory effect on F. oxysporum, whereas the inhibition rate of the leaves extract (with $50 \%$ methanol) on F. oxysporum is $25.37 \%$ and is up to $36.94 \%$ with the pure methanol extract. With the increase of concentration of methanol extract, the antifungal potency of $A$. annua leaves extract also increases. Similar tendency is observed for $F$. solani (Figure $2 \mathrm{~B}_{1}, \mathrm{~B}_{2}$ ). In contrast, the extracts from the other parts rather than leaves are almost inactive against F. solani. And the methanol extract from the leaves is found to be the most active toward $F$. solani, revealing that antifunfal agents are mainly present in A. annua leaves.

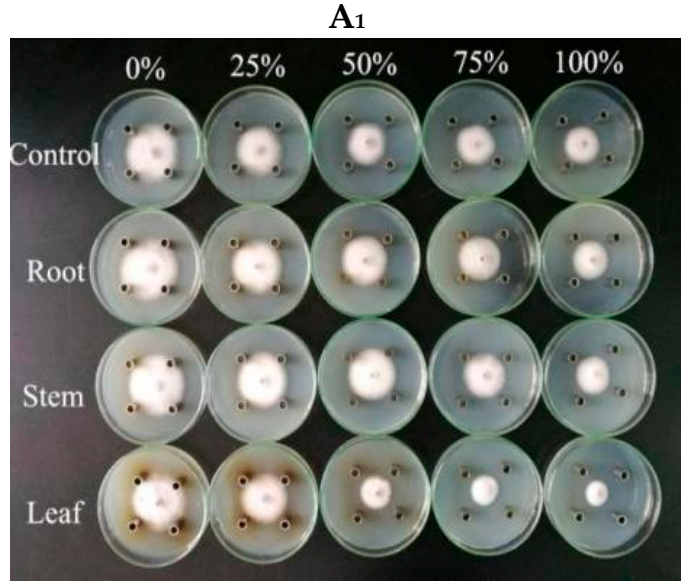

$\mathbf{A}_{2}$

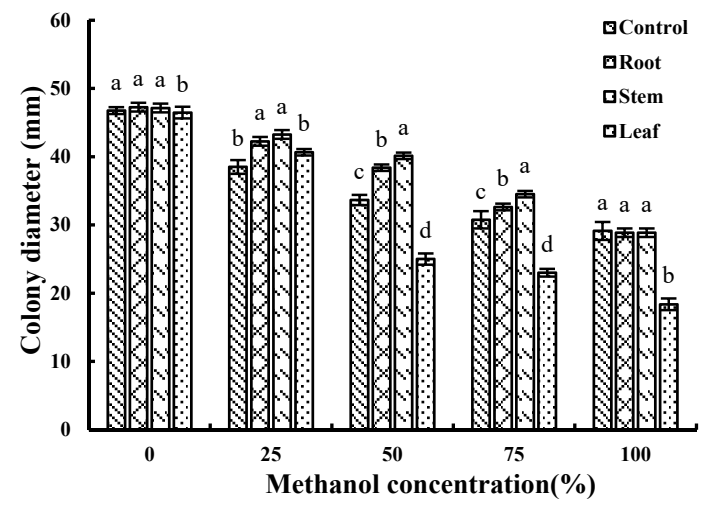

$\mathbf{B}_{1}$

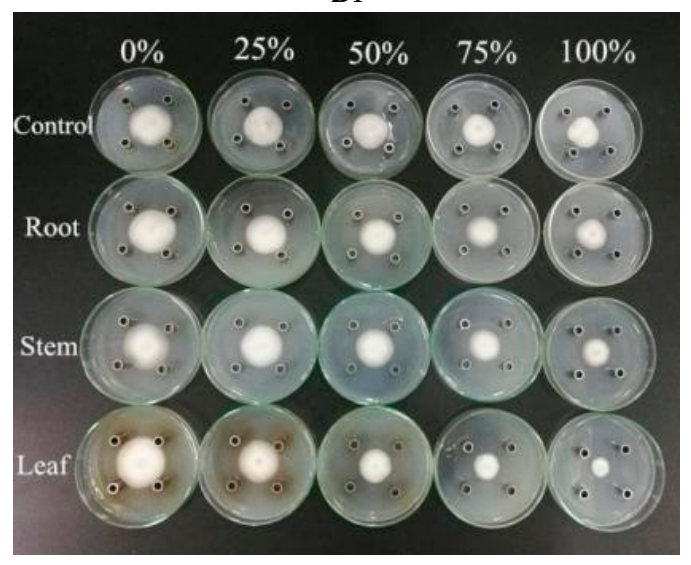

$\mathbf{B}_{2}$

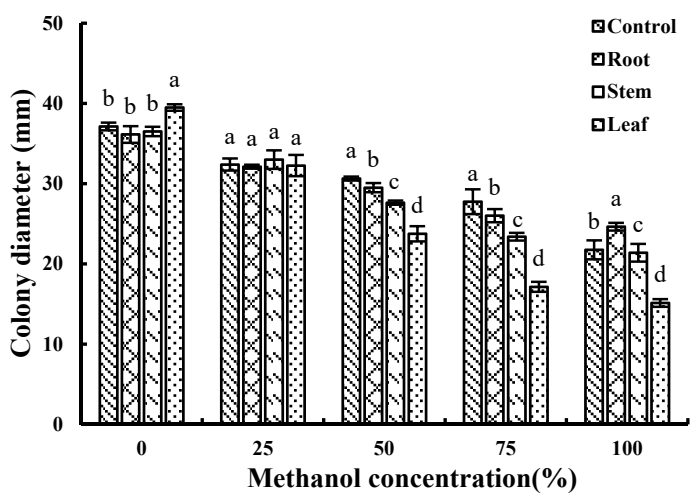

Figure 2. (A $\left.\mathbf{A}_{\mathbf{1}}\right)$ : Effects of different concentrations of methanol crude extracts from $A$. annua against F. oxysporum, and the mycelium growth for 5 days. $\left(\mathbf{B}_{1}\right)$ : Effects of different concentrations of methanol extracts from A. annua on F. solani. ( $\left.\mathbf{A}_{\mathbf{2}}\right)$ : The colony diameter $(\mathrm{mm})$ of F. oxysporum by treated with different crude extracts. $\left(\mathbf{B}_{2}\right)$ : The colony diameter $(\mathrm{mm})$ of $F$. solani by treated with different crude extracts. Note: Different letters represent significant differences $(p<0.05)$ among different plant parts at the same methanol concentration, while with the same letters mean no significant difference $(p>0.05)$.

\subsection{Inhibitory Effect of Fractions II-VII from A. annua Leaves on the Fungi}

To unveil the active fractions, EO and non-volatile fractions were rationally prepared and examined. As shown in Figure 3, the EO (II) from A. annua leaves has the most significant inhibitory effect on the mycelial growth of $F$. oxysporum (Figure $3 \mathrm{~A}_{1}, \mathrm{~A}_{2}$ ) and $F$. solani (Figure $3 \mathrm{~B}_{1}, \mathrm{~B}_{2}$ ) with the inhibition rates of $77.16 \%$ and $54.64 \%$, respectively. Secondary is fraction VII extracted directly by ultrasound. Fractions IV and V have relatively weak suppression on the pathogenic fungi, whereas the 
inhibitory effects of water soluble (III) and chloroform soluble (VI) on two pathogens are almost negligible. Collectively, the pathogens are sensitive to A. annua EO, disclosing that antifungal activity of $A$. апnиa leaves is mainly resulted from volatile components rather than non-volatile substances.

A1

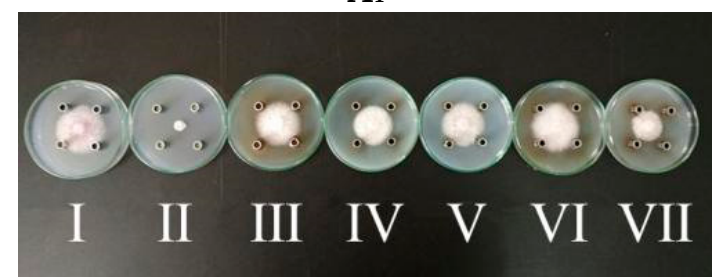

$\mathrm{A}_{2}$

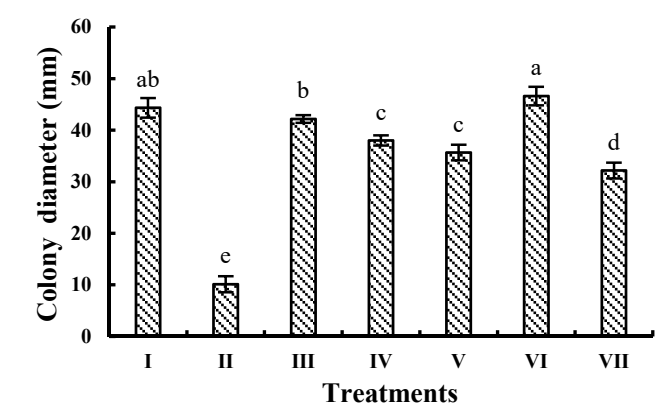

$\mathbf{B}_{1}$

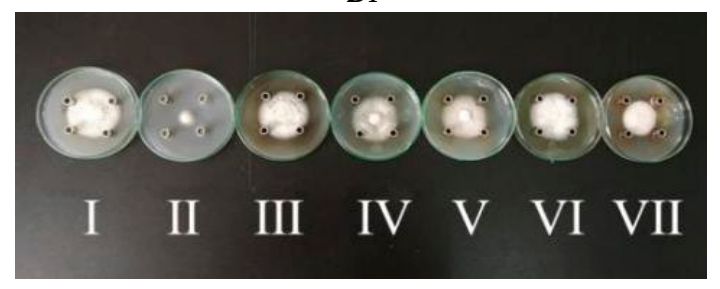

$\mathbf{B}_{2}$

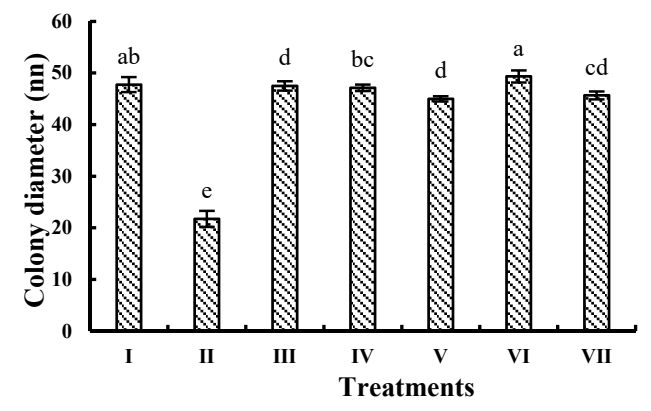

Figure 3. Inhibitory effect of fractions II-VII from A. annua on F. oxysporum and F. solani. $\mathbf{A}_{1}$ : The mycelium growth of $F$. oxysporum for 5 days. $\mathbf{B}_{1}$ : The mycelium growth of $F$. solani for five days. $\mathbf{A}_{\mathbf{2}}$ : The colony diameter $(\mathrm{mm})$ of $F$. oxysporum under different components. $\mathbf{B}_{2}$ : The colony diameter (mm) of F. solani under different components. I: Negative control; II: EO; III: Water soluble extract; IV: Methanol soluble extract; V: Chloroform soluble extract; VI: Water soluble extract; VII: Methanol soluble extract directly extracted by ultrosonic method. Note: In the same figure, different letters represent significant differences $(p<0.05)$ among different treatments, while with the same letters mean no significant difference $(p>0.05)$.

\subsection{Analysis of A. annua EO Chemical Components by GC-MS}

To get an insight into the chemical profile of $A$. annua volatile mixtures, the $A$. annua EO was obtained by steam distillation described above with a yield of $0.18 \%$, which was subsequently submitted to GC-MS analysis. As shown in Table 1, a total of 58 compounds are identified, accounting for $89.39 \%$ of the whole EO composition. The principal compound in A. annua EO is camphor $(23.48 \%)$, followed by germacrene $\mathrm{D}(9.06 \%), \beta$-caryophyllene $(5.39 \%)$, and camphene $(4.42 \%)$, respectively.

\subsection{MIC Determination of A. annua EO and Main Compounds}

To understand active compounds responsible for antigungal activity of EO, the MIC of A. annua $\mathrm{EO}$ and the abundant compounds were compared. As shown in Table 2, L-camphor; DL-camphor, $\beta$-caryophyllene, and camphene are all active toward F. oxysporum with MIC values of $0.11 \mathrm{mg} / \mathrm{mL}$, $0.14 \mathrm{mg} / \mathrm{mL}, 0.13 \mathrm{mg} / \mathrm{mL}$, and $0.16 \mathrm{mg} / \mathrm{mL}$, respectively, comparable to those of A. annua EO and two positive controls (flutriafol and hymexazol). For F. solani, it is also sensitive to L-camphor; DL-camphor, $\beta$-caryophyllene, and camphene with respective MIC value of $0.31 \mathrm{mg} / \mathrm{mL}, 0.16 \mathrm{mg} / \mathrm{mL}, 0.23 \mathrm{mg} / \mathrm{mL}$, and $0.22 \mathrm{mg} / \mathrm{mL}$, equivalent to those of $\mathrm{EO}(0.37 \mathrm{mg} / \mathrm{mL})$, flutriafol $(0.11 \mathrm{mg} / \mathrm{mL})$, and hymexazol $(0.16 \mathrm{mg} / \mathrm{mL})$. 
Table 1. Chemical composition and content of EO from A. annua.

\begin{tabular}{|c|c|c|c|}
\hline NO & R T (min) & Compounds & Percent Area (\%) \\
\hline 1 & 2.62 & 2-Hexenal & 0.25 \\
\hline 2 & 3.57 & $\alpha$-Pinene & 1.67 \\
\hline 3 & 3.79 & Camphene & 4.42 \\
\hline 4 & 4.22 & $\beta$-Pinene & 1.28 \\
\hline 5 & 4.33 & Myrcene & 0.40 \\
\hline 6 & 5.04 & $p$-Cymene & 0.54 \\
\hline 7 & 5.21 & Cineole & 1.84 \\
\hline 8 & 5.76 & Artemisia ketone & 1.05 \\
\hline 9 & 5.99 & trans-Sabinene hydrate & 0.13 \\
\hline 10 & 6.49 & $\alpha$-Terpinolene & 0.89 \\
\hline 11 & 7.53 & $\alpha$-Campholene aldehyde & 0.13 \\
\hline 12 & 8.26 & Camphor & 23.48 \\
\hline 13 & 8.65 & Pinocarvone & 0.42 \\
\hline 14 & 8.75 & Borneol & 0.67 \\
\hline 15 & 9.09 & D-Carvone & 0.53 \\
\hline 16 & 9.49 & $\alpha$-Terpineol & 0.19 \\
\hline 17 & 9.69 & Myrtenol & 0.54 \\
\hline 18 & 10.42 & $(-)$-Carveol & 0.23 \\
\hline 19 & 14.65 & trans-Chrysanthenylacetat & 0.32 \\
\hline 20 & 15.44 & Eugenol & 0.27 \\
\hline 21 & 15.61 & cis-Carvyl acetate & 0.15 \\
\hline 22 & 16.15 & $\alpha$-Copaene & 0.96 \\
\hline 23 & 16.54 & 3-Methyl-butanoic acid phenylmethyl ester & 0.69 \\
\hline 24 & 17.01 & cis-Jasmone & 0.19 \\
\hline 25 & 17.88 & Caryophyllene & 5.39 \\
\hline 26 & 18.17 & $\beta$-Gurjunene & 0.13 \\
\hline 27 & 19.09 & $\alpha$-Caryophyllene & 0.45 \\
\hline 28 & 19.23 & trans- $\beta$-Farnesene & 1.64 \\
\hline 29 & 19.37 & $\gamma$-Curcumene & 0.27 \\
\hline 30 & 19.96 & Selina-4(15),7(11)-diene & 1.39 \\
\hline 31 & 20.26 & Germacrene D & 9.06 \\
\hline 32 & 20.42 & $\beta$-Selinene & 3.19 \\
\hline 33 & 20.76 & Bicyclogermacrene & 1.43 \\
\hline 34 & 21.42 & $\gamma$-Cadinene & 0.50 \\
\hline 35 & 21.76 & $\delta$-Cadinene & 0.69 \\
\hline 36 & 23.28 & Nerolidol & 0.51 \\
\hline 37 & 23.67 & Nootkatone & 1.14 \\
\hline 38 & 23.98 & 5-Butyl-3-methyl-1,2,3,8A-tetrahydroindolizine & 1.25 \\
\hline 39 & 25.15 & $\alpha$-Cedrol & 0.51 \\
\hline 40 & 25.73 & 6,7-Dimethyltetralin & 0.84 \\
\hline 41 & 25.89 & Cadina-3,9-diene & 1.69 \\
\hline 42 & 26.18 & tau-Muurolol & 1.10 \\
\hline 43 & 26.65 & $(-)-a-$ Cadinol & 1.36 \\
\hline 44 & 27.01 & Isopyrethrone & 1.02 \\
\hline 45 & 27.84 & Ledane & 2.14 \\
\hline 46 & 28.25 & Caryophylla-2(12),6(13)-dien-5 $\alpha$-ol & 0.42 \\
\hline 47 & 28.34 & 7-Hydroxy-6-propanoylcoumarin & 0.52 \\
\hline 48 & 28.98 & Zierone & 0.99 \\
\hline 49 & 30.01 & 10,10-Dimethyl-4-acetyl-tricyclo[5.2.2.0(1,5)]Decane & 0.59 \\
\hline 50 & 30.32 & $( \pm)$-Nootkatone & 0.86 \\
\hline 51 & 30.54 & $6 \beta$-Hydroxy-1,10-dehydrofuranoeremophil-9-one & 0.61 \\
\hline 52 & 30.81 & Cyclogeranyl bromide & 3.63 \\
\hline 53 & 31.05 & 4-Phenyl-2-thiazolylamine & 0.83 \\
\hline 54 & 32.48 & 1,5-Dimethyl-2,6,7,7a-tetrahydro-1H-indene-3-carbaldehyde & 1.01 \\
\hline 55 & 33.24 & Artemisinic acid & 0.11 \\
\hline 56 & 35.79 & 3-Methyl-7-methoxy-2-benzopyran-1(1H)-one & 1.73 \\
\hline 57 & 37.16 & Hexadecanoic acid & 0.65 \\
\hline 58 & 37.99 & Dispiro[5,2,5,2]hexadecan-1-one & 0.49 \\
\hline
\end{tabular}

Note, RT: Retention time. 
Table 2. MIC values of $A$. annua $\mathrm{EO}$ and compounds against fungi (mg/mL).

\begin{tabular}{|c|c|c|c|c|c|c|c|}
\hline & EO & Flutriafol & Hymexazol & L-Camphor & DL-Camphor & $\beta$-Caryophyllene & Camphene \\
\hline F. oxysporum & $0.22 \pm 0.03^{a}$ & $0.10 \pm 0.02^{b}$ & $0.12 \pm 0.02^{b}$ & $0.11 \pm 0.02^{b}$ & $0.14 \pm 0.04^{\mathrm{b}}$ & $0.13 \pm 0.01^{\mathrm{b}}$ & $0.16 \pm 0.03^{\mathrm{ab}}$ \\
\hline F. solani & $0.37 \pm 0.08^{\mathrm{a}}$ & $0.11 \pm 0.02^{c}$ & $0.16 \pm 0.00 b^{c}$ & $0.31 \pm 0.06^{\mathrm{ab}}$ & $0.16 \pm 0.05^{b c}$ & $0.23 \pm 0.03^{a b c}$ & $0.22 \pm 0.03 \mathrm{abc}$ \\
\hline
\end{tabular}

\subsection{Evaluation of the Synergistic Action of A. annua EO and Chemical Fungicides}

The FIC indices in combination with $A$. annua $\mathrm{EO}$ and hymexazol or flutriafol were given in Table 3. According to the FICI values, the combined use of $A$. annua $\mathrm{EO}$ and flutriafol shows additive (0.75) inhibitory effect on F. solani, while the effects on F. oxysporum is irrelevant (1.25). At the same time, the results reveal the additive effect (0.63) on inhibiting F. oxysporum and synergistic (0.38) effect on inhibiting F. solani, when A. annua EO combined with hymexazol.

Table 3. The FICI values by combining $A$. annua $\mathrm{EO}$ with chemical fungicides.

\begin{tabular}{ccccc}
\hline & \multicolumn{2}{c}{ EO + Flutriafol } & \multicolumn{2}{c}{ EO + Hymexazol } \\
\cline { 2 - 5 } & FICI & Results & FICI & Results \\
\hline F. oxysporum & 1.25 & Irrelevant & 0.63 & Additive \\
F. solani & 0.75 & Additive & 0.38 & Synergic \\
\hline
\end{tabular}

$\mathrm{FICI} \leq 0.5$, synergism effect; $0.5<\mathrm{FICI} \leq 1$, additive effect; $1<\mathrm{FICI} \leq 4$, irrelevant. effect; FICI $>4$, antagonism.

\subsection{Effect of the Petroleum Ether Extract from A. annua on the Incidence of Infected P. notoginseng}

In vivo tests were needed to check whether the in vitro active agents make sense for the living $P$. notoginseng. To satisfy the requirement of in vivo experiment, the petroleum ether extract from A. annua leaves, which simulates the components of $A$. апnиa $\mathrm{EO}$, was prepared and mixed into the culture medium. As shown in Table 4, the petroleum ether extract could reduce the occurrence of P. notoginseng root-rot in a certain concentration. When the concentration of the petroleum ether extract is $0.5 \mathrm{mg} / \mathrm{g}$, the incidence of the plants is $25.00 \%$, which can decrease by $47.22 \%$. Additionally, the disease index of the infected plants is 13.10, which is also significantly lower than that of the negative control.

Table 4. Effect of the petroleum ether extract from A. annua on disease index and incidence of P. notoginseng plants infected by pathogenic fungi.

\begin{tabular}{cccc}
\hline \multirow{2}{*}{ Difference Targets } & \multicolumn{3}{c}{ Concentration $(\mathbf{m g} / \mathbf{m L})$} \\
\cline { 2 - 4 } & Control & $\mathbf{0 . 2 5}$ & $\mathbf{0 . 5}$ \\
\hline Disease index & $72.23 \pm 9.58^{\mathrm{a}}$ & $16.67 \pm 9.60^{\mathrm{b}}$ & $13.10 \pm 7.42^{\mathrm{b}}$ \\
Incidence $(\%)$ & $72.22^{\mathrm{a}}$ & $27.78^{\mathrm{b}}$ & $25.00^{\mathrm{b}}$ \\
\hline
\end{tabular}

Note: In the same line, different letters mean significant difference $(p<0.05)$, while with the same letters mean no significant difference $(p>0.05)$.

\section{Discussion}

Root-rot is a world-wide soil-borne disease, which can seriously damage many crops and medicinal plants and limit the continuous development of agriculture. P. notoginseng root-rot can occur in one- or two-year growth of $P$. notoginseng, whereas the occurrence rate of $P$. notoginseng older than two years is more severe [21]. Chemical fungicides are a double-edged sword which guaranteed the agricultural development but also bring serious pollution and harm to ecology and environment or human health [22]. Flutriafol and hymexazol are economically important agricultural chemicals, which are able to control several diseases affecting a wide range of crops. However, their high mobility potential in the soil makes them problematic fungicides. Indeed, flutriafol is a potentially toxic chemical 
fungicide, which may disrupt fertility in women and affect the endocrine system [23]. In contrast to chemical fungicides, botanical fungicides are wanted in agriculture. In consequence, it is very urgent to look for new compounds from natural material to develop new kinds of high efficiency, low toxicity fungicides. In the study, the results showed that F. oxysporum and F. solani have strong pathogenicity to $P$. notoginseng. After infection for a period of time, P. notoginseng appears the disease symptoms with yellowing of leaves and rot of roots (Figure 1). By comparing the potency of the methanol extracts with roots, stems, and leaves from $A$. annua, it was found that the extracts from $A$. annua with different methanol concentrations have various antifungal activities. The antifungal effect of $A$. annua leaves extracted by pure methanol is the strongest (Figure 2). When the methanol concentration reached $100 \%$, the antifungal activity on various fungi is the most significant. At the same time, when the extraction method is the same, the antifungal activity of leaves extract is the best, while the effect of roots is the worst. Some studies showed that the ethanol extract from A. annua could inhibit mycelium growth of Cytospora chrysosperma and Guignardia laricina, and its inhibition rates are 100\% and 91.74\%, respectively [24]. Therefore, an effort was made to know what kinds of substances in $A$. annua leaves are active. Then solvents with different polarity were used for fractionation and antifungal evaluation. The results reveal that $A$. annua $\mathrm{EO}$ is the most active, whereas the inhibitory effects of water soluble substances are negligible (Figure 3). By comparing the potency of different fractions, it might infer that EO is responsible for the major antifungal activity of A. annua. According to the others' studies, the antifungal activity of $A$. annua EO was evaluated against economically important foliar and soil borne fungal pathogens of tomato, which has revealed that A. annua EO is active against Sclerotinia sclerotiorum, Botrytis cinerea, Phytophthorainfestans, and Verticillim dahliae [25]. They also have suggested that $A$. annua $\mathrm{EO}$ could be used as potential antifungal agents to treat or prevent the pathogenic fungi. In the previous study, EOs from either Alpinia officinarum Hance and Amomum tsao-ko (Zingiberaceae) are found to have a good inhibition against the F. oxysporum, F. solani, and C. destrutans [26], and the EOs of Alpinia Katsumadai Hayata and Zingiber officinal Roscoe also have significant reductions in the mycelium growth of the pathogen in vitro [27]. This is corroborated by our findings. The results uncover that the main ingredients are camphor, camphene, germacrene $\mathrm{D}$, and $\beta$-caryophyllene (Table 1 ), which accounted for $42.35 \%$ of the total EO. Perazzo et al. has extracted EO from A. annua and identified 25 compounds including camphor $(43.5 \%)$, macrocarbene D $(16.0 \%)$, trans-pinocarveol (11.0\%), and herb-cymene (9.0\%) [28]. The EO in the analysis revealed a great variability both in the qualitative and quantitative composition. Chemical profile is generally influenced by the harvesting season, fertilizer, and the $\mathrm{pH}$ of soils, the choice and stage of drying conditions, the geographic location, chemotype or subspecies, and choice of part plant or genotype or extraction method [29]. Some study showed that the yield and main components of the EOs extracted from A. annua are varied at different flowering stages. The highest amounts of the main components were recorded in the full flowering stage, which main compounds are artemisia ketone (28.30-37.15\%), camphor (18.00-23.30\%), and 1,8-cineole (9.00-10.39\%) [30]. Then, the MIC values against F. oxysporum and F. solani were determined with the A. annua EO and the main compounds (Table 2). The results prove that the pathogenic fungi show a high sensibility to $A$. annua EO and the main compounds, with MIC ranging from 0.09 to $0.37 \mathrm{mg} / \mathrm{mL}$.

Previous study showed that 14-hydroxyltajixanthone, which was isolated from the solidsubstrate fermentation culture of Emericella sp. XL029 associated with the leaves of P. notoginseng, exhibited significant activity against Rhizoctonia cerealis, Fusarium oxysporum, and Physalospora piricola, with MIC value of $25 \mu \mathrm{g} / \mathrm{mL}$ [31]. Even though the MIC results varied among the tested strains, in most cases, the MIC values of $A$. annua $\mathrm{EO}$ and the main compounds were equivalent to the MIC values of chemical fungicides. The A. annua $\mathrm{EO}$ is a complex mixture of different compounds, so it is difficult to attribute the EO antifungal activity to a single or a particular constituent. In addition to the major components, also minor components may make a significant contribution to the antifungal activity. Following the results above, in order to further understand the antifungal mechanism of EO from $A$. annua, the extract can be isolated and purified, and the antifungal mechanism with the 
structure-activity relationship of the active substance could be discussed in more depth in the future. Research showed that the interactions between antifungal substances could be divided into four types: synergistic, additive, irrelevant, and antagonistic [32]. In our experiment, for the purpose of improving the efficiency of fungi inhibition, the antifungal activity between $A$. annua EO and the chemical fungicides of hymexazol and flutriafol were studied. The results indicates that when $A$. annua EO was used in combination with hymexazol or hymexazol, the growth of tested strains could be effectively inhibited at a much lower concentration (Table 3), and the synergistic or additive effects were exhibited while the antifungal effect was not affected. The existence of synergies could greatly reduce the use of chemical pesticides, which can not only reduce the cost, ensure the safety, but also reduce the fungicide residue in traditional Chinese medicine. Since the difference in quantity and quality between the compound composition of $\mathrm{EO}$ and the active compound group of single drug, a new active compound group is formed, which can lead to some new different pharmacodynamics [33]. Therefore, the pharmacological effects of the new ingredients need to be further studied. For further simulating the antifungal effect of $A$. annua $\mathrm{EO}$ in vivo, the petroleum ether extract was prepared from $A$. annua leaves to conduct an in vivo experiment. The results revealed that the petroleum ether extract could reduce the incidence of infected $P$. notoginseng plants in a certain concentration range (Table 4). The major inhibitory effect is resulted from the EO components of the petroleum ether extract (Figure S1). The results of in vitro experiments show that the A. annua EO has certain inhibitory effect on the growth of mycelia and the germination of conidia. Therefore, it is speculated that the addition of A. annua EO to the soil may inhibit the pathogenic fungi germination of pathogenic and mycelial growth, which could inhibit the pathogenic fungi from infecting the plants of P. notoginseng. Finally, it would reduce the plants incidence and disease index. Nevertheless, the EO effects on the other soil microbial and plants need to be further studied. Some studies have indicated that botanical fungicides, such as matrine and garlicin, are likely to be a panacea for sustainable agricultural development and sustainable stability of the ecological environment survival despite their mild effects [34]. A. annua is widely distributed in China and has a high yield. Particularly, its EO has a good inhibitory effect on bacteria and fungi. The present findings of antifungal property of EO from $A$. annua against root rot pathogenic fungi might lend supports for developing $A$. annua as a natural fungicide especially beneficial for P. notoginseng root rot disease.

\section{Conclusions}

Our previous field experiments found that covering $A$. annua on the surface of soils could promote the growth of $P$. notoginseng, increase the content of chlorophyll, and promote plant height and dry weight of roots. The incidence of the disease was significantly lower than that of P. notoginseng without covering A. annua, which greatly inhibited the occurrence of yellow rot [35]. This observation inspired us to clarify why $A$. annua could reduce the root rot disease of $P$. notoginseng. In this study, it was found that F. oxysporum and F. solani have strong pathogenicity to $P$. notoginseng. The extracts from A. annua leaves other than the roots, stems are the most active. Moreover, volatile components from $A$. annua EO were found to be the strongest. GC-MS analysis reveal the chemical profile of $A$. annua $\mathrm{EO}$, and further antifungal tests disclose antifungal potency of camphor, camphene and $\beta$-caryophyllene against F. oxysporum and F. solani, equivalent to the MIC values of chemical fungicides. This study also found that A. annua EO could reduce the concentration of hymexazol or hymexazol, two chemical fungicides, indicating their synergistic effects. Finally, an in vivo experiment revealed that the petroleum ether extract (simulating EO) could reduce the incidence of infected P. notoginseng plants, in accordance with our previous field experiments. Our efforts resulted in EO of $A$. annua and the main compounds thereof are active agents towards fungal species associated with $P$. notoginseng root-rot disease, which will be beneficial for the pharmaceutical industry of $P$. notoginseng.

Supplementary Materials: The following are available online at http:/ / www.mdpi.com/1420-3049/24/1/213/ s1. 
Author Contributions: Y.-X.C. and X.D. designed the experiment, analyzed the data, and wrote the paper. Y.-N.M., C.-J.C. and Q.-Q.L. performed the experiments. F.-R.X. commented the manuscript. All authors have read and approved the manuscript.

Funding: This work was supported by the the National Natural Science Foundation of China (81660626, 81273408), the National Key Research and Development Program of China "Research and Development of Comprehensive Technologies on Chemical Fertilizer and Pesticide Reduction and Synergism" (2017YFD0201402), Yunnan Provincial Science and Technology Department-Applied Basic Research Joint Special Funds of Yunnan University of Traditional Chinese Medicine (2017FF116 (-014)), the Yunnan Applied basic Research Program (2015FB139), and the Fourteenth Candidates of the Young Academic Leaders of Yunnan Province to Min XU (2011CI044).

Conflicts of Interest: The authors declare no competing financial interest.

\section{References}

1. Xue, P.; Yang, X.S.; Sun, X.Y.; Ren, G.X. Antifungal activity and mechanism of heat-transformed ginsenosides from notoginseng against Epidermophyton floccosum, Trichophyton rubrum, and Trichophyton mentagrophytes. RSC Adv. 2017, 7, 10939-10946. [CrossRef]

2. Sha, M.C.; Zhou, Y.F.; Zhang, H.Z.; Li, Y.; Qin, Q. Study on differences of chemical components in different parts of Panax notoginseng. Mod. Chin. Med. 2018, 20, 832-836.

3. Liu, D.H.; Xu, N.; Guo, L.P.; Jin, Y.; Cui, X.M.; Yang, Y. Qualitative characteristics and classification study on commodity specification and grade standard of Panax notoginseng. China J. Chin. Mater. Med. 2016, 41, 776-785.

4. Yang, M.; Mei, X.Y.; Zhen, J.F.; Yin, Z.B.; Zhao, Z.; Zhang, X.D.; He, X.H.; Zhu, S.S. Sensitivity of the pathogens of Panax notoginseng to ginsenosides. Plant Prot. Sci. 2014, 40, 76-81.

5. Miao, C.P.; Mi, Q.L.; Qiao, X.G.; Zheng, Y.K.; Chen, Y.W.; Xu, L.H.; Guan, H.L.; Zhao, L.X. Rhizospheric fungi of Panax notoginseng: Diversity and antagonism to host phytopathogens. J. Ginseng Res. 2016, 40, 127-134. [CrossRef] [PubMed]

6. Miao, Z.Q.; Li, S.D.; Liu, X.Z.; Chen, Y.J.; Li, Y.H.; Wang, Y.; Guo, R.J.; Xia, Z.Y.; Zhang, K.Q. The causal microorganisms of Panax notoginseng root rot disease. Agric. Sci. China 2006, 39, 1371-1378.

7. Tan, Y.; Cui, Y.S.; Ji, X.L.; Wei, Y.L.; Cui, X.M. Research progress in microorganism changes of rhizospheric soil and root endogenous and ecology during continuous cropping of Panax notoginseng. Chin. Tradit. Herb. Drugs 2017, 48, 391-399.

8. Chee, H.Y.; Lee, M.H. In vitro activity of celery essential oil against Malassezia furfur. Mycobiology 2009, 37, 67-68. [CrossRef]

9. Zhang, C.; Qiu, F.; Li, J.; Wang, M.Y.; Gong, M.X. The effects of arteannuin B, arteannuic acid and scopoletinon pharmacokinetics of artemisinin inmice. Global Tradit. Chin. Med. 2016, 9, 394-398.

10. Zhang, Y.Q.; Ding, W.; Zhao, Z.M.; Wu, J.; Fan, Y.H. Acaricidal bioactivity of different growth period Artemisia annua extracts against Tetranychus cinnabarinus. Chin. J. Ecol. 2007, 26, 1969-1973.

11. Bianca, I.; Anca, M.; Andreia, C. Sesquiterpene Lactones from Artemisia Genus: Biological Activities and Methods of Analysis. J. Anal. Methods Chem. 2015, 2015, 1-21.

12. Wu, J.; Ding, W.; Zhang, Y.Q.; Guo, W.M. Antifungal activities of primary extracts of Artemisia annua L. against two fungi. Agrochemicals 2007, 46, 713-715.

13. Bilia, A.R.; Santomauro, F.; Sacco, C.; Bergonzi, M.C.; Donato, R. Essential oil of Artemisia annua L.: An extraordinary component with numerous antimicrobial properties. J. Evidence-Based Complement. Altern. Med. 2014, 2014, 59819. [CrossRef]

14. Hao, Y.; Yang, S.Y.; Zhang, X.H.; Shen, H.M.; Yue, X.L.; Luo, L.Y. Effect of Acremonium hans fordii spores suspension on germination and growth of several crops seedling. J. Gansu Agric. Univ. 2016, 51, 95-101.

15. Zhang, J.H.; Li, M.; Zhang, B.; Ma, T.Z.; Chen, X.; Han, S.Y. Comparison of antimicrobial activity of eight monomer polyphenols to wine microorganisms. Food Ferment. Ind. 2016, 42, 101-106.

16. Xue, X.L.; Zhang, X.H.; Sun, P.; Cui, Y.; Wang, X.C.; Kong, L.Y. Analysis of volatile oil from six kinds of medicinal plants in Changbai mountain province by GC-MS. J. Chin. Med. Mater. 2016, 39, 1062-1066.

17. Nikkhah, M.; Hashemi, M.; Najafi, M.B.H.; Farhoosh, R. Synergistic effects of some essential oils against fungal spoilage on pear fruit. Int. J. Food Microbiol. 2017, 257, 285-294. [CrossRef] 
18. Gutierrez, J.; Barry-Ryan, C.; Bourke, P. The antimicrobial efficacy of plant essential oil combinations and interactions with food ingredients. Int. J. Food Microbiol. 2008, 124, 91-97. [CrossRef]

19. Sharma, A.; Rajendran, S.; Srivastava, A.; Sharma, S.; Kundu, B. Antifungal activities of selected essential oils against Fusarium oxysporum $f$. sp. lycopersici 1322, with emphasis on Syzygium aromaticum essential oil. J. Biosci. Bioeng. 2017, 123, 308-313. [CrossRef]

20. Shanmugam, V.; Kanoujia, N. Biological management of vascular wilt of tomato caused by Fusarium oxysporum $f$. sp. lycospersici by plant growth-promoting rhizobacterial mixture. Biol. Control 2011, 57, 85-93. [CrossRef]

21. Chen, Y.J.; Wang, Y.; Wang, Q.F.; Ma, C.S.; Li, S.D.; Wu, Z.C.; Li, Y.H. Studies on prevention and control of root rot disease of Panax Notoginseng application of seed dressing (seedling) with compound agent and soil fumigation. China. J. Chin. Mater. Med. 2008, 33, 1329-1331.

22. Kland, M.J. Chapter 8-teratogenicity of pesticides and other environment pollutants. Stud. Environ. Sci. 1988, 31, 315-463.

23. Santana, M.B.; Rodrigues, K.J.A.; Durán, R.; Alfonso, M.; Vidal, L.; Campos, F.; De Oliveira, I.M.; Faro, L.R.F. Evaluation of the effects and mechanisms of action of flutriafol, a triazole fungicide, on striatal dopamine release by using in vivo microdialysis in freely moving rats. Ecotoxicol. Environ. Saf. 2009, 72, 1565-1571. [CrossRef]

24. Han, X.B.; Ma, L.; Ma, W.; Wang, H.; Tian, J. Antifungal activity study of effective substance extracted from Artenisia using different methods. For. Eng. 2008, 24, 13-16.

25. Soylu, E.M.; Yigitbas, H.; Tok, F.M.; Soylu, S.; Kurt, S.; Baysal, O.; Kaya, A.D. Chemical composition and antifungal activity of the essential oil of Artemisia annua L. against foliar and soil-borne fungal pathogens. J. Plant Dis. Prot. 2005, 11, 229-239.

26. Sun, W.M.; Ma, Y.N.; Yin, Y.J.; Chen, C.J.; Xu, F.R.; Dong, X.; Cheng, Y.X. Effects of Essential Oils from Zingiberaceae Plants on Root-Rot Disease of Panax notoginseng. Molecules 2018, 23, 1021. [CrossRef]

27. Yin, Y.J.; Chen, C.J.; Guo, S.W.; Li, K.M.; Ma, Y.N.; Sun, W.M.; Xu, F.R.; Cheng, Y.X.; Dong, X. The Fight Against Panax notoginseng Root-Rot Disease Using Zingiberaceae Essential Oils as Potential Weapons. Front Plant Sci. 2018, 9, 14. [CrossRef]

28. Juteau, F.; Masotti, V.; Bessiere, J.M.; Dherbomez, M.; Viano, J. Antibacterial and antioxidant activities of Artemisia annua essential oil. Fitoterapia 2002, 73, 532-535. [CrossRef]

29. Marzoug, H.N.B.; Romdhane, M.; Lebrihi, A.; Mathieu, F.; Couderc, F.; Abderraba, M.; Khouja, M.L.; Bouajila, J. Eucalyptus oleosa essential oils: Chemical composition and antimicrobial and antioxidant activities of the oils from different plant parts (stems, leaves, flowers and fruits). Molecules 2011, 16, 1695-1709. [CrossRef]

30. Cosge Senkal, B.; Kiralan, M.; Yaman, C. The Effect of Different Harvest Stages on Chemical Composition and Antioxidant Capacity of Essential Oil from Artemisia annua L. Tarim. Bilim. Derg. 2015, 21, 71-77. [CrossRef]

31. Wu, X.; Fang, L.Z.; Liu, F.L.; Pang, X.J.; Qin, H.L.; Zhao, T.; Xu, L.L.; Yang, D.F.; Yang, X.L. New prenylxanthones, polyketide hemiterpenoid pigments from the endophytic fungus Emericella sp XL029 and their anti-agricultural pathogenic fungal and antibacterial activities. RSC Adv. 2017, 7, 31115-31122. [CrossRef]

32. Gao, Z.L.; Chen, Y.; Xie, Y.H. In vitro antimicrobial activity of essential oil from Artemisia annua. Food Sci. 2010, 31, 209-211.

33. Davidson, P.M.; Parish, M.E. Methods for testing the efficacy of food antimicrobials. Food Technol. 1989, 43, 148-155. 
34. Zhang, X.; Wu, Z.F.; Li, W.; Ma, Z.Q.; Feng, J.T. New progress in research and development of botanical pesticides. Pestic. Sci. Adm. 2013, 34, 22-27.

35. Zhao, Y.M.; Ma, Y.N.; Chen, C.J.; Cheng, Y.X.; Dong, X.; Xu, F.R. Inhibition effects of water soluble extract from Artemisia annua leaves on the growth of rhizosphere Fusarium oxysporum associated with Panax notoginseng. Nat. Prod. Res. Dev. 2018, 30, 373-378.

Sample Availability: Samples of the compounds are available from the authors.

(C) 2019 by the authors. Licensee MDPI, Basel, Switzerland. This article is an open access article distributed under the terms and conditions of the Creative Commons Attribution (CC BY) license (http:/ / creativecommons.org/licenses/by/4.0/). 